\title{
Is Face Age Mapped Asymmetrically onto Space? Insights from a SNARC-like Task
}

\author{
Mario Dalmaso ${ }^{1, *(D)}$ and Michele Vicovaro ${ }^{2, *(D)}$ \\ 1 Department of Social and Developmental Psychology, University of Padova, 35131 Padova, Italy \\ 2 Department of General Psychology, University of Padova, 35131 Padova, Italy \\ * Correspondence: mario.dalmaso@unipd.it (M.D.); michele.vicovaro@unipd.it (M.V.)
}

Citation: Dalmaso, M.; Vicovaro, M. Is Face Age Mapped Asymmetrically onto Space? Insights from a SNARC-like Task. Symmetry 2021, 13, 1617. https://doi.org/10.3390/ sym13091617

Academic Editor: Pecchinenda Anna

Received: 28 July 2021

Accepted: 30 August 2021

Published: 3 September 2021

Publisher's Note: MDPI stays neutral with regard to jurisdictional claims in published maps and institutional affiliations.

Copyright: (c) 2021 by the authors. Licensee MDPI, Basel, Switzerland. This article is an open access article distributed under the terms and conditions of the Creative Commons Attribution (CC BY) license (https:// creativecommons.org/licenses/by/ $4.0 /)$.

\begin{abstract}
The magnitude associated with a stimulus can be spatially connoted, with relatively smaller and larger magnitudes that would be represented on the left and on the right side of space, respectively. According to recent evidence, this space-magnitude association could reflect specific brain asymmetries. In this study, we explored whether such an association can also emerge for face age, assuming that responders should represent relatively younger and older adult faces on the left and on the right, respectively. A sample of young adults performed a speeded binary classification task aimed at categorising the age of a centrally placed adult face stimulus as either younger or older than the age of a reference face. A left-side and a right-side response key were used to collect manual responses. Overall, older faces were categorised faster than younger faces, and response latencies decreased with the absolute difference between the age of the target stimulus and the age of the reference, in line with a distance effect. However, no evidence of a left-to-right spatial representation of face age emerged. Taken together, these results suggest that face age is mapped onto space differently from other magnitudes.
\end{abstract}

Keywords: SNARC-like effect; distance effect; age; face; hemispheric asymmetry; social cognition

\section{Introduction}

A prominent phenomenon emerging from the scientific literature on human cognition is that magnitudes of different nature can be spatially represented. In this regard, the most classic example involves the numerical domain, with relatively smaller and larger numbers that are typically associated with the left and the right part of space, respectively. Typically, this left-to-right spatial representation of numbers can be unveiled through a behavioural task consisting in classifying, by means of a manual key press, a centrally presented digit as either smaller (e.g., ' 1 ') or greater (e.g., ' 9 ') than a reference digit (e.g., ' 5 '). Importantly, the two response keys are typically placed on two opposite spatial locations along the horizontal axis. As a main result, faster responses are generally reported when small and large numbers are responded to with the left- and right-side response keys, compared to when the opposite mapping (i.e., small-right/large-left) is used. This phenomenon is referred to as the spatial-numerical association of response codes, or SNARC effect [1], and it can emerge even when the number magnitude is task-irrelevant, that is, when digits are classified as either odd or even rather than as smaller or larger than a reference, thus indicating that number magnitude can be extracted automatically [1]. Moreover, in the numerical domain, another interesting and well-known phenomenon is the so-called 'distance effect' [2], according to which the time required to make a comparison between two numbers (e.g., which number is the largest?) is inversely correlated with the distance between the two. The SNARC and the distance effects have led to the hypothesis that numbers are spatially represented along a 'mental number line' (MNL) oriented from left to right. Specifically, according to the MNL construct, small and large numbers would be preferentially associated with the left and the right side of space, respectively, which would explain the SNARC effect. Moreover, longer distances on the MNL would be 
associated with an increased discriminability of number pairs, which would also explain the distance effect.

Although the SNARC effect has been widely replicated and investigated under many different conditions and tasks [3], its origins are still debated. On the one hand, the fact that the direction of the SNARC effect can be shaped by reading habits-for instance, it can go from right to left among Arabs [4]—speaks in favour of culturally based roots. On the other hand, recent studies using non-symbolic numerical magnitudes (e.g., dots) have provided supporting evidence for a SNARC effect, even among newborns [5] and nonhuman animal species [6]. This is a remarkable result that questions the cultural origins of the SNARC and that, according to some authors, would arise because of specific brain asymmetries influencing magnitude processing [7-9]. For instance, according to one of these accounts [8], given that the left hemisphere would be more strongly engaged by positive valenced stimuli (or approaching behaviours) and the right hemisphere with negative valenced stimuli (or withdrawal behaviours) [10], one may assume that relatively small magnitudes would be coupled with negative emotions (i.e., 'less' could be associated, for instance, with the concept of 'scarcity'; e.g., scarcity in food, resources, etc.), whereas relatively large magnitudes would be coupled with positive emotions. If the possible origins of the SNARC effect can be found within a biological dimension, it is also true that additional variables (e.g., cultural and/or situational differences) can later intervene in further shaping its direction (e.g., from left to right, or the contrary; see also [11-13]).

Of particular relevance for the present work, the spatial mapping of magnitudes can also embrace nonnumerical variables such as time [14], size [15], or weight [16], confirming that 'less' is associated with the left side of space, and 'more' with the right one. For instance, as for the time dimension, in [14] relatively short (i.e., 1 s) and long (e.g., 3 s) durations were responded to faster with a left- and right-side response key, respectively, compared to when the opposite mapping (i.e., short-right/long-left) was used. Intriguingly, some studies have also tried to unveil whether SNARC-like effects could be also detected within a social domain by employing human faces, which are likely the most complex and information-rich social stimuli that our brain is constantly called upon to process. To the best of our knowledge, all these studies focused on facial expressions-which are known to shape a variety of cognitive mechanisms pervasively, such as memory [17] or attention [18] - reporting evidence for the notion that both emotional valence and intensity can be horizontally spatialised (i.e., negative/low-intensity and positive/higher-intensity emotions would be mapped on the left and on the right, respectively), at least under some circumstances [19-22]. Interestingly, some studies employing neutral or emotional faces within a SNARC-like task have also reported evidence of a spatial representation of magnitude reflected in eye movements $[23,24]$, which are known to be heavily shaped by these important social stimuli [25]. Overall, all of these works are of great relevance because they provide novel evidence not only for the space-magnitude literature, but also for the face processing domain, which is one of the building blocks of social interactions [26].

In the present work, we wanted to further investigate the potential role of social variables conveyed by faces in eliciting a SNARC-like effect by focusing on another important dimension characterising individuals, namely their age. Indeed, in our daily life, it is undoubtful that we tend to shape our social behaviour according to the age of the person we are interacting with. For instance, our social behaviour can be exceptionally different when interacting with a relatively young person (e.g., a children) or an older one (e.g., an elderly). Hence, it is not surprising that a variety of studies reported that face age, similarly to facial expressions, can also deeply modulate cognition [27,28]. Moreover, the case of face age is rather peculiar because, differently from other facial variables, such as the strict dichotomy deriving from biological gender (that generally remain stable for the whole life of an individual), or the richer range of facial expressions (which can vary quickly and for several times per day, according to both endogenous and exogenous stimuli), face age can be seen as a succession of different magnitudes whose development is linear and relatively slow, and definitely not under volitional control (excluding peculiar external 
factors; e.g., aesthetic surgery). For this reason, it is highly likely that adults should possess rather defined and stable mental representations of faces belonging to different age categories, similarly to the defined and stable mental representations of number magnitudes. On this basis, we developed a SNARC-like task related to face age, trying to remain as adherent as possible to standard approaches employed to reveal the classic SNARC effect with number stimuli [1]. In particular, participants had to categorise the age of a centrally placed adult target face as either younger (i.e., 20, 30, or 40 years old) or older (i.e., 60, 70, or 80 years old) than a reference face belonging to an individual of 50 years old. Critically, in one block of trials (i.e., the congruent condition), the younger faces had to be classified with a left-side key and the older faces with a right-side key, whereas in another block of trials (i.e., the incongruent condition), the response mapping was inverted (i.e., younger-right, older-left). In so doing, we expected to observe a SNARC-like effect for face age, with faster responses emerging in the congruent than in the incongruent condition, similarly to what is typically observed within the numerical domain. Moreover, additional evidence of a potential relationship between face age and space could be provided by the distance effect. For this reason, we also expected that the greater the absolute difference between the age of the target face and the age of the reference face, the shorter the latencies associated with the manual response.

\section{Materials and Methods}

\subsection{Participants}

Since we planned to analyse our data through linear mixed effects models including both subjects and items as random effects, the sample size was estimated following the main guidelines for such a data analysis approach [29]. More specifically, these guidelines suggest that each experimental condition should be associated with at least 1600 observations. In the present context, in which we intended to collect 60 trials per experimental condition, at least 27 participants were therefore necessary. We stopped at $n=30$ for convenience at the end of a booking session. The sample was composed of young adults (mean age $=22.1$ years, $\mathrm{SD}=1.88$, mode $=21$, range $=20$ to $29 ; 10$ males) with normal or corrected-to-normal vision, recruited at the University of Padova. Two participants declared being left-handed. Manual preference was also assessed by asking participants to complete the Edinburgh Handedness Inventory (EHI) short form [30]. This tool gives a handedness score along a scale varying from -100 (i.e., total preference for the left hand) to +100 (i.e., total preference for the right hand). Here, the mean EHI score was $+73.75(\mathrm{SD}=44.81$; mode $=+87.5$; range $=-100$ to +100$)$. Furthermore, following the EHI classification scale [30], two participants were actually categorised as left-handed (i.e., EHI scores $=-100 ;-62.5)$ and another participant as mixed-handed (i.e., EHI score $=+37.5)$. All other participants $(n=27$, mean age $=22.04$ years, $\mathrm{SD}=1.95$, mode $=21$, range $=20$ to $29 ; 9$ males $)$ were classified as right-handed (i.e., $\mathrm{EHI}$ mean score $=+86.57$; $\mathrm{SD}=11.97$; mode $=+87.5$; range: +62.5 to +100$)$.

\subsection{Stimuli and Apparatus}

Face stimuli, extracted from the FACES database [31], consisted of photographs of 24 individuals (half males and half females) displaying a neutral expression. To exclude potential social confounds, all faces belonged to White individuals (i.e., the same ethnic group of the participants). Importantly, the FACES database offers rating scores for the perceived age of each face stimulus as declared by different groups of observers of different ages. Since we planned to collect data among young adults, we selected facial stimuli by using the mean perceived age declared by female and male young adult observers. In so doing, three face categories younger than 50 years $(20,30$, and 40 years old), and other three face categories older than 50 years $(60,70$, and 80 years old) were created. Each category comprised two female and two male identities whose perceived face age precisely corresponded to-or, in a few cases, closely approached-the age of the category. Two additional faces, belonging to one male and one female with a perceived age of 50 years old, 
served as the 'reference' stimuli on which participants were asked to rely to complete the age classification task successfully. The use of facial stimuli belonging to a relatively wide age range and to both genders also has the advantage of increasing the ecological validity of the results since it mimics the variety of individuals we typically meet during everyday social interactions. For the sake of clarity, all identification codes associated with each face model can be found in a dedicated file (please see the Data Availability Statement).

\subsection{Apparatus}

A PC running E-Prime 2 was used to handle stimulus presentation and collect manual responses. Stimuli were presented on a PC monitor $(1920 \times 1080 \mathrm{px}, 60 \mathrm{~Hz})$ placed $57 \mathrm{~cm}$ from the participant. The screen background was set to grey $(R=192, G=192, B=192)$. A standard keyboard was used to collect manual responses.

\subsection{Experimental Procedure}

Firstly, participants were involved in a SNARC-like task, which was divided in two main blocks. At the beginning of each block, the two 'standard' faces of 50 years old were presented separately for $10 \mathrm{~s}$ each at the centre of the screen (see also Figure 1). Participants were informed about the age of the standard faces and they were asked to pay attention to both of them. Then, the first block started. Each trial began with a black fixation cross (side: $1^{\circ}$ ) presented at the centre of the screen for $700 \mathrm{~ms}$, followed by a central facial stimulus (about $8^{\circ}$ width $\times 12^{\circ}$ height). Participants were asked to classify-as fast and accurately as possible- the face as belonging to either an individual younger than 50 y.o. or older than 50 y.o. by pressing one of two horizontally aligned response keys (i.e., the ' $\mathrm{d}$ ' and ' $\mathrm{k}$ ' keys). They were also instructed to look at the centre of the screen for the whole duration of the trial. The face remained visible until a response was detected or $1500 \mathrm{~ms}$ elapsed, whichever came first. Then, a central visual feedback appeared for $500 \mathrm{~ms}$, consisting of a green ' $\mathrm{O}^{\prime}$ (side: $1^{\circ}$ ) in case of a correct response, and a red ' $X^{\prime}$ (side: $1^{\circ}$ ) in case or either a wrong or a missed response. Finally, a blank screen was presented for $800 \mathrm{~ms}$. There were two practise blocks of 10 trials (i.e., 20 practice trials in total), both followed by an experimental block of 120 trials (i.e., 240 experimental trials in total; 2 blocks $\times 6$ age categories $\times 4$ faces $\times$ 5 repetitions). In order to control for any potential order effect, face stimuli were always presented in a random order. The association between age (i.e., younger vs. older than 50 y.o.) and response side (i.e., left vs. right) was inverted in two blocks; namely, in one block, younger faces were responded with the left key and older faces with the right key (i.e., congruent block), while in the other block, the opposite occurred (i.e., incongruent block). The block order was counterbalanced across participants. Secondly, at the end of SNARC-like task, participants completed a computerised version of the EHI [30].

A. Learning phase

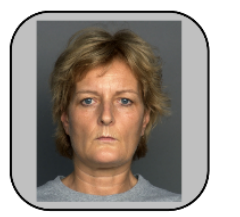

Reference face $10 \mathrm{~s}$
B. Experimental phase

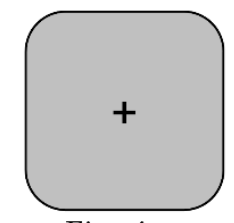

Fixation $700 \mathrm{~ms}$

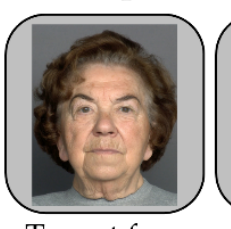

Target face

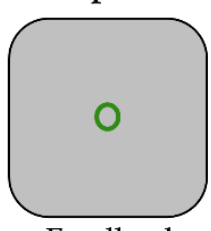

Feedback $500 \mathrm{~ms}$

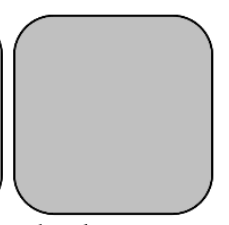

Blank screen $800 \mathrm{~ms}$

\section{Examples of stimuli}
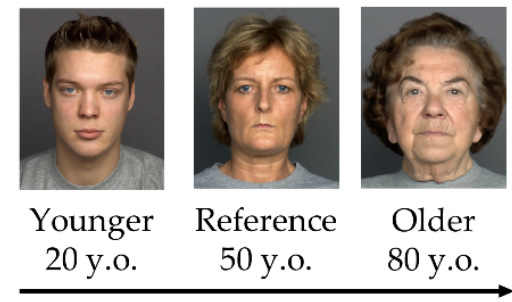

Perceived face age

Figure 1. (A) Example of a reference face stimulus depicting a 50-year-old (y.o.) female face; (B) example of a trial in which an older female face is depicted alongside a green " $\mathrm{O}$ ", indicating a correct response; (C) examples of face stimuli used in the experiment. None of the stimuli are drawn to scale. Note: our experimental face stimulus set was comprised of FACES database [31] models whose identification codes can be found in a dedicated file (please see the Data Availability Statement). These models are not depicted here to comply with the conditions of use of the FACES database. 


\section{Results}

\subsection{Data Handling}

Data were handled and analysed through R software. Missing responses $(0.31 \%$ of trials) and trials with a wrong response $(2.33 \%$ of trials) were removed and not further analysed because of their low percentage. Correctly responded trials with a latency smaller or greater than $3 \mathrm{SD}$ from each participant's mean (computed separately for each condition) were classified as outliers and removed as well (1.9\% of trials).

\subsection{Analyses of the SNARC-like Effect}

The latencies of correctly responded trials were analysed through a linear mixed model. Several models were computed through the lmer package [32], ranging from the null model to the saturated one. Then, the likelihood ratio test was used to select the best model fitting data, which included, as the fixed effects, face age (2: younger vs. older), response side (2: left vs. right), and their interaction. As random effects it included the intercepts for subjects and face stimuli (i.e., the 24 face identities). The lmerTest package [33] was then used to submit the model to a Type 1 ANOVA (Satterthwaite's approximation for degrees of freedom). This revealed that the main effect of face age was significant, $F(1,22)=4.314, p=0.0497$, with smaller latencies in response to older faces $(M=557 \mathrm{~ms}$, $S E=14)$ than to younger faces $(M=581 \mathrm{~ms}, S E=14)$. The main effect of response side was also significant, $F(1,6822)=9.409, p=0.002$, with smaller latencies associated with the right-side key $(M=565 \mathrm{~ms}, S E=12.9)$ than the left-side key $(M=573 \mathrm{~ms}, S E=12.9)$, likely reflecting the fact the most participants were righthanded. Importantly, the face age $\times$ response side interaction was not significant, $F(1,6822)=0.508, p=0.476$. This unexpected latter result indicates the absence of a SNARC-like effect elicited by face age (see also Figure 2, panel A).
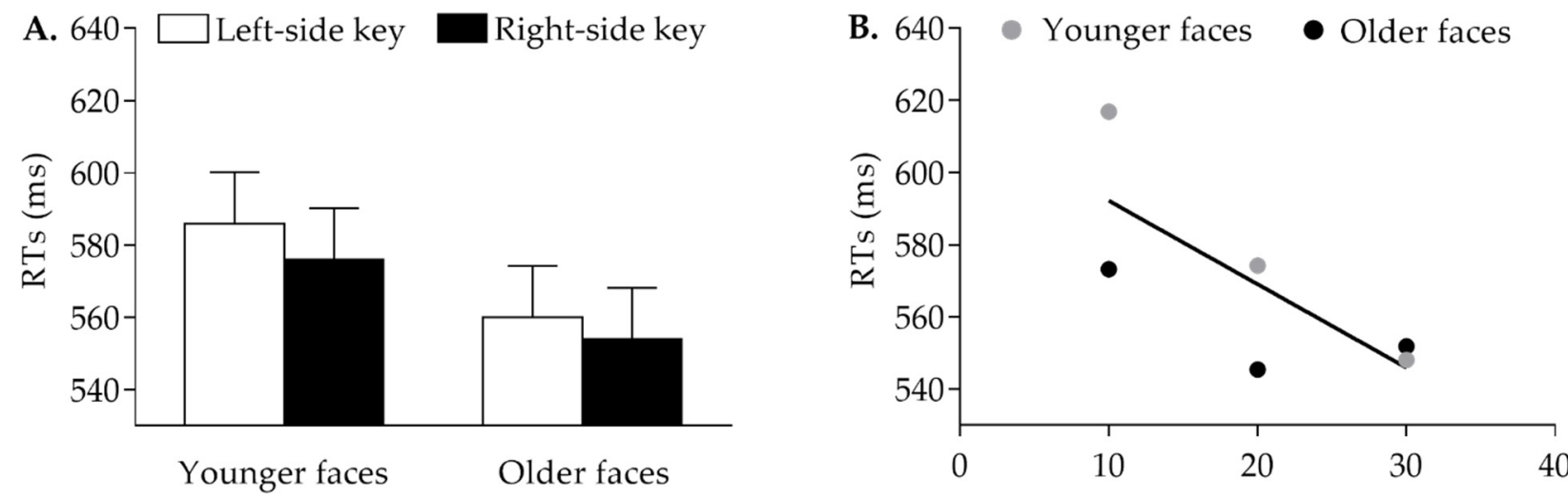

Abs(Target face age - Reference face age)

Figure 2. (A) Mean latencies as a function of face age (younger vs. older) and response side (left vs. right). Error bars are SEM; (B) mean latencies as a function of the absolute difference between the age of each target face (i.e., 20, 30, 40, 60, 70, 80 years old) and the age of the reference faces (i.e., 50 years old). Please note that the regression line had $615.316 \mathrm{~ms}$ as the intercept value and -2.311 as the slope value.

\subsection{Analyses of the Distance Effect}

Evidence of a distance effect would imply a linear decrease in response latencies as the absolute distance between the age of the target face increases with respect to the age of the reference face. Hence, we firstly computed the absolute difference between the age of each target face (i.e., 20, 30, 40, 60, 70, and 80 years old) and the age of the two reference faces (i.e., 50 years old). Then, RTs were analysed, independently of response side, through a linear mixed model in which the absolute age difference between the target and the reference faces was entered as the fixed effect, while the intercepts for subjects and face stimuli were entered as the random effects. A statistically significant negative relationship 
between absolute age difference and RTs emerged, $b=-2.311$, SEb $=0.6, t(21.937)=-3.853$, $p<0.001$, indicating the presence of the distance effect (see also Figure 2, panel B).

\subsection{Relationship between Handedness and the SNARC-like Effect}

Finally, because there is evidence showing an association between the degree of handedness and the degree to which participants tend to represent concepts in space [34], the EHI score of each participant was correlated with an overall index of the SNARClike effect. The index was computed in the following manner: $\mathrm{M}_{i}=\left[\mathrm{RT}_{i}(\right.$ younger, right $)$ - $\mathrm{RT}_{i}$ (younger, left)] $+\left[\mathrm{RT}_{i}(\right.$ older, left $)-\mathrm{RT}_{i}($ older, right $\left.)\right]$, where $\mathrm{M}_{i}$ represents the magnitude of the SNARC-like effect associated with the $i$ th participant, $\mathrm{RT}_{i}$ (younger/older, right) and $\mathrm{RT}_{i}$ (younger/older, left) represent the mean latencies associated with the $i$ th participant when responding to younger or older target faces with the right-side and left-side key, respectively. The stronger the link between younger-left and older-right, the greater the $\mathrm{M}_{i}$ value. In the present context, a positive correlation would have denoted a positive relationship between the degree of right-hand preference and the strength of the left-to-right spatial representation of face age. Nevertheless, a non-significant negative correlation emerged, $b=-0.121, S E b=0.301, t(24)=-0.400, p=0.692$

\section{Discussion}

This work aimed to reveal whether face age, intended as a succession of different magnitudes, can give rise to a SNARC-like effect [35], with relatively young and old faces that should be mapped onto the left and right side of space, respectively. To reach this goal, several target face identities, belonging to different age groups, had to be classifiedby means of a speeded manual response provided with left- and right-side keys-as either younger or older than a reference face. The possible link between face age and space was also expected to be revealed through the so-called distance effect, consisting of faster latencies as the absolute distance between the age of the target and the reference face increases.

Importantly-and unexpectedly-no evidence of a SNARC-like effect emerged, as testified by the absence of the interaction between face age and response side. However, a reliable distance effect was instead reported, which suggests that face age magnitudes were actually processed by participants. Despite this latter evidence, it appears that the processing of face age failed to be translated into a clear left-to-right horizontal spatial representation; we speculate that this may have occurred for two main reasons. First, in the present context, we decided to manipulate face age as similarly as possible to what is typically carried out for eliciting the SNARC effect, namely, by presenting participants with a succession of age magnitudes (i.e., 20, 30, 40, 60, 70, and 80 years old; in the SNARC effect, digits 1-4 and 6-9 are typically used [1]) and providing them with an age reference characterised by a fixed value (i.e., 50 years old; in the SNARC effect, digit 5 is typically used [1]). If, on the one hand, this approach could allow one to draw comparisons with previous studies on the SNARC effect, it is also possible that it was less than optimal to induce a mental representation of face age as arranged along a continuum. Indeed, because each different age category was associated with different identities, it cannot be excluded that this context may have hindered a representation of age as an incrementing magnitude, thus weakening the potential spatial representation of age. More precisely, the use of different identities may have induced participants to build up an exemplar-based social perception of faces, which, in turn, may have weakened the mental construction of a clear left-to-right spatial vector. This possibility seems to be further supported by the fact that individuals are particularly skilled in extracting face identity throughout age progression, which is an essential ability to maintain the track of familiar faces and, in turn, navigate successfully within social settings [36]. For this reason, it may be speculated that a mental representation of age as a continuous magnitude could potentially emerge when a singular personal identity is employed (e.g., a specific individual getting older). In so doing, making face identity a fixed property, responders would be immerged in a context 
that may facilitate a clearer and stronger face representation along the age dimension. In this regard, it is interesting to note that supporting evidence for a left-to-right spatial representation of face age has been found in a study [37] in which participants saw two photos of Woody Allen presented in succession, and then they were asked to decide if the second photo depicted him in either an earlier or later time point of his life with respect to the first photo. Although the task employed in that study [37] strongly deviates from what is typically used to elicit both SNARC and SNARC-like effects-and the use of a famous face identity may be associated with some temporal confounders (e.g., participants could associate the age of famous individuals with precise historical periods rather than with the biological age per se) - the idea of manipulating face age within the same face identity may be an important element to be considered to reveal possible associations between face age and the left-to-right spatial domain. Currently, and to the best of our knowledge, we are not aware of any standardised face database composed of photos of the same individuals collected at different time points of their lives. Alternatively, we do not exclude that specific photo-editing software could be employed to artificially introduce aging to a set of standard faces, thus mimicking biological aging of specific individuals. Future works are therefore necessary, and they could also employ inverted faces (see also [38]), as they represent a perfect control condition to take into account any potential confounding effects due to low-level perceptual differences among stimuli. Second, a possible explanation for the lack of a SNARC-like effect for face age could call into question more subtle mechanisms contributing to building up the mental representation of magnitude and, more generally, concepts. In this regard, it is important to recall that the valence-other than the magnitude-associated with a stimulus appears to be spatially connoted as well, with relatively negative concepts associated with the left side of space, and relatively positive concepts with the right side $[22,39,40]$, at least among right-handed individuals [41]. As for the age dimension, several studies have reported that younger individuals are typically more positively connoted than older individuals [42,43]; therefore, one may speculate that younger and older faces would be more easily associated with the right and left side of space, respectively. This, in turn, may have introduced a source of conflict with the left-to-right spatial vector potentially deriving from age magnitude, thus preventing the emergence of the SNARC-like effect. Unfortunately, since we do not have a measure concerning age bias within our sample, this latter consideration must be taken with caution and additional studies are needed.

Even if face age failed to interact with the response side, it led to a significant main effect, with older faces that were responded to faster than younger faces. Although we did not make any specific predictions about this result, it appears to resemble what is reported in a few previous studies documenting an advantage in the categorisation of faces belonging to a different age group than that of the responder [44-46]. In our specific case, because our sample was composed of individuals aged between 20 and 29 years, we believe it is reasonable to assume that they have broadly identified themselves as belonging to the 'younger' - rather than to the 'older' - face category. Overall, the main effect of age seems to align with the well-known phenomenon known as the other-race categorisation advantage $[47,48]$, which consists of faster responses when the to-be-classified face belongs to a different ethnic group than that of the responder. Taken together, these two phenomena, related to age and ethnic group, would arise because faces belonging to an outgrouprather than to an ingroup-would be processed in less detail, thus leading to a relatively fast categorization [49].

Interestingly, if it is true that most of studies exploring the link between magnitude and space focused on the horizontal axis, it is also true that others focused on the vertical dimension, showing that smaller quantities are generally associated with the bottom part of space, and larger quantities with the top part. This bottom-to-top representation emerged for numbers [50], but also for non-numerical dimensions [51,52], leading to the common view that 'more is up'. The vertical representation of face age could therefore be another future avenue that might be worth exploring. Moreover, we also feel that, under some 
specific circumstances, it could be even more salient than the horizontal dimension. Indeed, from birth to adulthood, individuals not only grow in age, but they also grow in height, an aspect that could make the spatial mapping of age more adherent to the vertical, rather than horizontal, dimension, at least for faces belonging to a specific age range. Finally, future studies could also collect eye movements $[23,24]$ since, compared to manual responses, they are known to provide a richer data set [53-55] and represent a more sensitive and direct index of ongoing visual processing, or even neuroimaging measures, as facial and numerical stimuli would be treated by different cerebral regions $[56,57]$. Neural measures may also shed fresh light on the role of possible functional hemispheric asymmetries [58] in handling face age dimension.

\section{Conclusions}

In this work, faces belonging to different ages did not elicit a SNARC-like effect, but they led to a distance effect. This pattern of results may reflect the fact that faces are complex stimuli whose social interpretation is multifaceted. This, in turn, could lead to a compound mapping of face age within space and, more generally, to a more complex mental representation of this social dimension as compared, for instance, to the numerical domain. Taken together, these results may be informative for both social cognition (i.e., face processing mechanisms) and the SNARC-like domain (i.e., spatial representational of social magnitudes).

Author Contributions: Conceptualization, M.D. and M.V.; methodology, M.D. and M.V.; software, M.D. and M.V.; validation, M.D. and M.V.; formal analysis, M.D. and M.V.; investigation, M.D. and M.V.; resources, M.D. and M.V.; data curation, M.D. and M.V.; writing-original draft preparation, M.D. and M.V.; writing—review and editing, M.D. and M.V.; visualization, M.D. and M.V.; supervision, M.D. and M.V.; project administration, M.D. and M.V.; funding acquisition, M.D. and M.V.; All authors have read and agreed to the published version of the manuscript.

Funding: This research was supported by a grant from MIUR (Dipartimenti di Eccellenza DM 11/05/2017 n. 262) to the Department of General Psychology, University of Padova, and by an individual grant (DPSS-SID2019) to M.D.

Institutional Review Board Statement: The study was approved by the Ethics Committee for Psychological Research at the University of Padova (approval code: 1882; approval date: 23 March 2016) and conducted in accordance with the Declaration of Helsinki.

Informed Consent Statement: Informed, written consent was obtained from all participants.

Data Availability Statement: Access to data on OSF at https:/ / doi.org/10.17605/OSF.IO/URTXZ (accessed on 31 August 2021).

Acknowledgments: We thank Elena Franchin for her assistance in data collection.

Conflicts of Interest: The authors declare no conflict of interest. The funders had no role in the design of the study; in the collection, analyses, or interpretation of data; in the writing of the manuscript, or in the decision to publish the results.

\section{References}

1. Dehaene, S.; Bossini, S.; Giraux, P. The mental representation of parity and number magnitude. J. Exp. Psychol. Gen. 1993, 122, 371-396. [CrossRef]

2. Moyer, R.S.; Landauer, T.K. Time required for judgements of numerical inequality. Nature 1967, 215, 1519-1520. [CrossRef]

3. Wood, G.; Willmes, K.; Nuerk, H.-C.; Fischer, M.H. On the cognitive link between space and number: A meta-analysis of the SNARC effect. Psychol. Sci. 2008, 50, 489-525.

4. Shaki, S.; Fischer, M.H.; Petrusic, W.M. Reading habits for both words and numbers contribute to the SNARC effect. Psychon. Bull. Rev. 2009, 16, 328-331. [CrossRef]

5. de Hevia, M.D.; Veggiotti, L.; Streri, A.; Bonn, C.D. At birth, humans associate "few" with left and "many" with right. Curr. Biol. 2017, 27, 3879-3884.e2. [CrossRef]

6. Rugani, R.; Vallortigara, G.; Priftis, K.; Regolin, L. Number-space mapping in the newborn chick resembles humans' mental number line. Science 2015, 347, 534-536. [CrossRef] 
7. Felisatti, A.; Laubrock, J.; Shaki, S.; Fischer, M.H. A biological foundation for spatial-numerical associations: The brain's asymmetric frequency tuning. Ann. N.Y. Acad. Sci. 2020, 1477, 44-53. [CrossRef] [PubMed]

8. Vallortigara, G. Comparative cognition of number and space: The case of geometry and of the mental number line. Philos. Trans. R. Soc. B Biol. Sci. 2018, 373, 20170120. [CrossRef] [PubMed]

9. De Hevia, M.D.; Girelli, L.; Addabbo, M.; Cassia, V.M. Human infants' preference for left-to-right oriented increasing numerical sequences. PLoS ONE 2014, 9, e96412. [CrossRef] [PubMed]

10. Davidson, R. Well-being and affective style: Neural substrates and biobehavioural correlates. Philos. Trans. R. Soc. London. Ser. B Biol. Sci. 2004, 359, 1395-1411. [CrossRef] [PubMed]

11. Walsh, V. A theory of magnitude: Common cortical metrics of time, space and quantity. Trends Cogn. Sci. 2003, 7, 483-488. [CrossRef]

12. Proctor, R.W.; Cho, Y.S. Polarity correspondence: A general principle for performance of speeded binary classification tasks. Psychol. Bull. 2006, 132, 416-442. [CrossRef]

13. Myachykov, A.; Scheepers, C.; Fischer, M.H.; Kessler, K. TEST: A tropic, embodied, and situated theory of cognition. Top. Cogn. Sci. 2013, 6, 442-460. [CrossRef]

14. Vallesi, A.; Binns, M.A.; Shallice, T. An effect of spatial-temporal association of response codes: Understanding the cognitive representations of time. Cognition 2008, 107, 501-527. [CrossRef] [PubMed]

15. Ren, P.; Nicholls, M.; Ma, Y.-Y.; Chen, L. Size matters: Non-numerical magnitude affects the spatial coding of response. PLoS ONE 2011, 6, e23553. [CrossRef] [PubMed]

16. Dalmaso, M.; Vicovaro, M. Evidence of SQUARC and distance effects in a weight comparison task. Cogn. Process. 2019, 20, 163-173. [CrossRef] [PubMed]

17. D'Argembeau, A.; Van der Linden, M. Facial expressions of emotion influence memory for facial identity in an automatic way. Emotion 2007, 7, 507-515. [CrossRef]

18. Pecchinenda, A.; Pes, M.; Ferlazzo, F.; Zoccolotti, P. The combined effect of gaze direction and facial expression on cueing spatial attention. Emotion 2008, 8, 628-634. [CrossRef]

19. Fantoni, C.; Baldassi, G.; Rigutti, S.; Prpic, V.; Murgia, M.; Agostini, T. Emotional semantic congruency based on stimulus driven comparative judgements. Cognition 2019, 190, 20-41. [CrossRef]

20. Holmes, K.J.; Lourenco, S.F. Common spatial organization of number and emotional expression: A mental magnitude line. Brain Cogn. 2011, 77, 315-323. [CrossRef]

21. Prete, G. Spatializing emotions besides magnitudes: Is there a left-to-right valence or intensity mapping? Symmetry 2020, 12, 775. [CrossRef]

22. Pitt, B.; Casasanto, D. Spatializing emotion: No evidence for a domain-general magnitude system. Cogn. Sci. 2017, 42, 2150-2180. [CrossRef] [PubMed]

23. Blanco, I.; Nieto, I.; Vazquez, C. Emotional SNARC: Emotional faces affect the impact of number magnitude on gaze patterns. Psychol. Res. 2021, 85, 1885-1893. [CrossRef]

24. Fernández, S.R.; Rahona, J.J.; Hervás, G.; Vázquez, C.; Ulrich, R. Number magnitude determines gaze direction: Spatial-numerical association in a free-choice task. Cortex 2011, 47, 617-620. [CrossRef] [PubMed]

25. Tatler, B.W.; Wade, N.J.; Kwan, H.; Findlay, J.M.; Velichkovsky, B.M. Yarbus, eye movements, and vision. i-Perception 2010, 1, 7-27. [CrossRef]

26. Little, A.C.; Jones, B.; DeBruine, L. The many faces of research on face perception. Philos. Trans. R. Soc. B Biol. Sci. 2011, 366, 1634-1637. [CrossRef] [PubMed]

27. Rhodes, M.G.; Anastasi, J.S. The own-age bias in face recognition: A meta-analytic and theoretical review. Psychol. Bull. 2012, 138, 146-174. [CrossRef]

28. Dalmaso, M.; Castelli, L.; Galfano, G. Social modulators of gaze-mediated orienting of attention: A review. Psychon. Bull. Rev. 2020, 27, 833-855. [CrossRef]

29. Brysbaert, M.; Stevens, M. Power analysis and effect size in mixed effects models: A tutorial. J. Cogn. 2018, 1, 9. [CrossRef]

30. Veale, J.F. Edinburgh handedness inventory-Short form: A revised version based on confirmatory factor analysis. Laterality 2013, 19, 164-177. [CrossRef] [PubMed]

31. Ebner, N.C.; Riediger, M.; Lindenberger, U. FACES-A database of facial expressions in young, middle-aged, and older women and men: Development and validation. Behav. Res. Methods 2010, 42, 351-362. [CrossRef]

32. Bates, D.; Mächler, M.; Bolker, B.; Walker, S. Fitting linear mixed-effects models using lme4. J. Stat. Softw. 2015, 67, 1-48. [CrossRef]

33. Kuznetsova, A.; Brockhoff, P.B.; Christensen, R.H.B. ImerTest package: Tests in linear mixed effects models. J. Stat. Softw. 2017, 82, 38433. [CrossRef]

34. Brunyé, T.T.; Gardony, A.; Mahoney, C.R.; Taylor, H.A. Body-specific representations of spatial location. Cognition 2012, 123, 229-239. [CrossRef] [PubMed]

35. MacNamara, A.; Loetscher, T.; Keage, H.A.D. Mapping of non-numerical domains on space: A systematic review and metaanalysis. Exp. Brain Res. 2017, 236, 335-346. [CrossRef] [PubMed]

36. Ramon, M.; Gobbini, M.I. Familiarity matters: A review on prioritized processing of personally familiar faces. Vis. Cogn. 2017, 26, 179-195. [CrossRef] 
37. Boroditsky, L.; Fuhrman, O.; McCormick, K. Do English and Mandarin speakers think about time differently? Cognition 2011, 118, 123-129. [CrossRef]

38. Maurer, D.; Le Grand, R.; Mondloch, C.J. The many faces of configural processing. Trends Cogn. Sci. 2002, 6, 255-260. [CrossRef]

39. Giuliani, F.; Manippa, V.; Brancucci, A.; Palumbo, R.; Tommasi, L.; Pietroni, D. How emotional is a banknote? The affective basis of money perception. Psychol. Res. 2021, 1-16. [CrossRef]

40. Root, J.C.; Wong, P.S.; Kinsbourne, M. Left hemisphere specialization for response to positive emotional expressions: A divided output methodology. Emotion 2006, 6, 473-483. [CrossRef]

41. Casasanto, D. Embodiment of abstract concepts: Good and bad in right and left-handers. J. Exp. Psychol. Gen. 2009, 138, 351-367. [CrossRef] [PubMed]

42. North, M.S.; Fiske, S.T. Modern attitudes toward older adults in the aging world: A cross-cultural meta-analysis. Psychol. Bull. 2015, 141, 993-1021. [CrossRef]

43. Chopik, W.J.; Giasson, H. Age differences in explicit and implicit age attitudes across the life span. Gerontologist 2017, 57, S169-S177. [CrossRef]

44. Johnston, R.A.; Kanazawa, M.; Kato, T.; Oda, M. Exploring the structure of multidimensional face-space: The effects of age and gender. Vis. Cogn. 1997, 4, 39-57. [CrossRef]

45. Craig, B.M.; Lipp, O.V. Facial age cues and emotional expression interact asymmetrically: Age cues moderate emotion categorisation. Cogn. Emot. 2017, 32, 350-362. [CrossRef]

46. Craig, B.M.; Lipp, O.V. The relationship between visual search and categorization of own and other-age faces. Br. J. Psychol. 2018, 109, 736-757. [CrossRef] [PubMed]

47. Levin, D.T. Classifying faces by race: The structure of face categories. J. Exp. Psychol. Learn. Mem. Cogn. 1996, $22,1364-1382$. [CrossRef]

48. Valentine, T.; Endo, M. Towards an exemplar model of face processing: The effects of race and distinctiveness. Q. J. Exp. Psychol. Sect. A 1992, 44, 671-703. [CrossRef] [PubMed]

49. Hugenberg, K.; Young, S.G.; Bernstein, M.J.; Sacco, D.F. The categorization-individuation model: An integrative account of the other-race recognition deficit. Psychol. Rev. 2010, 117, 1168-1187. [CrossRef] [PubMed]

50. Schwarz, W.; Keus, I.M. Moving the eyes along the mental number line: Comparing SNARC effects with saccadic and manual responses. Percept. Psychophys. 2004, 66, 651-664. [CrossRef]

51. Vicovaro, M.; Dalmaso, M. Is 'heavy' up or down? Testing the vertical spatial representation of weight. Psychol. Res. 2020, 85, 1183-1200. [CrossRef] [PubMed]

52. Rusconi, E.; Kwan, B.; Giordano, B.L.; Umiltà, C.; Butterworth, B. Spatial representation of pitch height: The SMARC effect. Cognition 2006, 99, 113-129. [CrossRef]

53. Dalmaso, M.; Castelli, L.; Scatturin, P.; Galfano, G. Trajectories of social vision: Eye contact increases saccadic curvature. Vis. Cogn. 2017, 25, 358-365. [CrossRef]

54. Dalmaso, M.; Castelli, L.; Galfano, G. Attention holding elicited by direct-gaze faces is reflected in saccadic peak velocity. Exp. Brain Res. 2017, 235, 3319-3332. [CrossRef] [PubMed]

55. Dalmaso, M.; Castelli, L.; Galfano, G. Early saccade planning cannot override oculomotor interference elicited by gaze and arrow distractors. Psychon. Bull. Rev. 2020, 27, 990-997. [CrossRef]

56. Fan, X.; Wang, F.; Shao, H.; Zhang, P.; He, S. The bottom-up and top-down processing of faces in the human occipitotemporal cortex. eLife 2020, 9, e48764. [CrossRef]

57. Yeo, D.; Wilkey, E.; Price, G.R. The search for the number form area: A functional neuroimaging meta-analysis. Neurosci. Biobehav. Rev. 2017, 78, 145-160. [CrossRef]

58. Demaree, H.; Everhart, D.; Youngstrom, E.; Harrison, D.W. Brain lateralization of emotional processing: Historical roots and a future incorporating "dominance". Behav. Cogn. Neurosci. Rev. 2005, 4, 3-20. [CrossRef] 